\title{
A interação entre fé e política na missão em perspectiva dialógica
}

\author{
The interaction between faith and politics in mission \\ from a dialogical perspective
}

Elias Wolff

\section{Resumo}

A proposta deste artigo objetiva compreender a missão da igreja vivida na interação entre fé e política. Fé expressa a adesão ao Evangelho do Reino da "vida em abundância" (Jo 10,10) na história humana; e política é entendida como serviço pelo bem comum na sociedade. A missão permite, e exige, interação dessas duas realidades, distintas, mas não antagônicas. A vulnerabilidade pela qual passa a humanidade nesses tempos de pandemia da COVID-19, clama das instituições sociais e religiosas, um agir conjunto para a superação dos graves problemas que daí emergem. A igreja é cooperadora na missão de Deus, contribuindo de forma efetiva nessa superação. Assim, a ação social é uma privilegiada expressão do Evangelho que gera vida e transforma tudo o que contradiz a vida. A missão no mundo atual configura um modo próprio de ser igreja e de ser cristão/ã, caracterizados/as pela "saída", em diálogo e cooperadora com as iniciativas que visibilizam o Reino em nosso meio. Trata-se de fidelidade à ação do Espírito que recria no hoje da história a prática de Jesus, que se expressa também no agir político entendido como uma forma privilegiada do exercício da caridade.

Palavras-chave: Missão. Fé. Política. Sociedade. Reino de Deus.

\section{Abstract}

The purpose of this article is to understand the mission of the church lived 
in the interaction between faith and politics. Faith expresses adherence to the Gospel of the Kingdom of "life in abundance" (Jn 10:10) in human history; and politics is understood as a service for the common good in society. The mission allows, and requires, the interaction of these two realities, which are distinct, but not antagonistic. The vulnerability that humanity is going through in these COVID-19 pandemic times, calls for social and religious institutions to act together to overcome the serious problems that emerge from it. The church is cooperative in the mission of God, contributing effectively to this overcoming. Thus, social action is a privileged expression of the Gospel that generates life and transforms everything that contradicts life. The mission in the current world is a way of being a church and of being a Christian, characterized by the "way out", in dialogue and cooperating with the initiatives that make the Kingdom visible in our midst. It is fidelity to the action of the Spirit that recreates the practice of Jesus in the history of today, which is also expressed in political action understood as a privileged form of the exercise of charity.

Keywords: Mission. Faith. Politics. Society. Kingdom of God.

\section{Introdução}

O presente artigo propõe refletir sobre a missão da igreja se realizando no vínculo entre fé e política. Missão é vida em sentido amplo, contextualizada socioculturalmente. Não se faz missão fora do contexto em que vivem os interlocutores da missão, e essa vida clama a igreja à missão. Por isso, a atividade missionária da Igreja, vai além da ideia meramente de salvar almas, busca a salvação integral da pessoa: corpo, espírito, mundo, cosmos e tempo. Neste sentido, fé e política interagem nos distintos espaços socio-eclesiais. Mantendo suas especificidades, esses espaços se complementam, pois ambos dizem respeito à vida.

Por "política" entende-se aqui o bem comum. Política relaciona-se à organização da vida e a mediação de conflitos. Sua finalidade refere-se aos vários aspectos na vida das pessoas em sociedade, tais como emprego, transporte, moradia, segurança e infraestrutura da cidade. ${ }^{1}$ A sociedade é uma

\footnotetext{
${ }^{1}$ CNBB Sul 2, Os cristãos e as eleições, p. 3.
} 
comunidade política, formada pelo conjunto das condições de vida social que permitem aos "indivíduos, famílias e associações alcançar facilmente a própria perfeição". ${ }^{2}$ E como a igreja situa-se no meio social, sua missão evangelizadora tem implicações nesse meio enquanto compromisso de fé pelo bem da comunidade toda. Tal é, por exemplo, o compromisso libertador do evangelho. ${ }^{3}$ Pode-se, então, dizer que a missão é um serviço ao Reino de Deus, na fidelidade ao Espírito que visa recriar, no hoje da história, a prática de Jesus em todos os âmbitos da sociedade. A missão não se limita à uma ação burocrática que se esgota no "fazer", mas é presença profética, amorosa e crítica da igreja, capaz de manifestar o amor e a misericórdia de Deus Pai e mãe aos homens e mulheres do nosso tempo.

Assim, a missão na qual dialoga a fé e a política torna-se uma resposta ao apelo do Papa Francisco de uma "igreja em saída" e de uma igreja compreendida em chave missionária, em "conversão pastoral". Isso exige o abandono das comodidades, como costuma-se dizer: "fez-se sempre assim". Para isso urge assumir, de forma ousada e criativa, a tarefa de repensar os objetivos, as estruturas, o estilo e os métodos evangelizadores das nossas comunidades. ${ }^{4}$

A igreja tem consciência que a missão que recebeu de Jesus é Evangelizar. E "evangelizar é tornar o Reino de Deus presente no mundo". ${ }^{5}$ Logo, a ação missionária não se dá apenas pela relação pessoal e vertical com Deus. ${ }^{6} \mathrm{O}$ horizonte e objetivo da missão é anunciar o Reino de Deus que se faz presente na história, transformando as situações que contradizem o Evangelho da "vida em abundância" (Jo 10,10) e construindo relações de fraternidade e solidariedade. A presença da igreja na sociedade muito tem a contribuir para situações políticas verdadeiramente humanas, fomentando relações de justiça e de serviço ao bem comum. Ela reforça convicções fundamentais acerca da verdadeira natureza da comunidade política, bem como, do fim, do reto exercício e dos limites da autoridade. ${ }^{7}$ Desse modo, a missão confiada aos discípulos, não é apenas uma tarefa, mas uma identidade e um modo de ser, ${ }^{8}$

\footnotetext{
${ }^{2}$ GS 74 .

${ }^{3} \mathrm{CNBB}$, Doc. 40, 213.

${ }^{4}$ EG 33 .

${ }^{5} \mathrm{EG} 176$.

${ }^{6} \mathrm{EG} 180$.

${ }^{7} \mathrm{GS} 73$.

${ }^{8}$ LG 9.
} 
que impele a vincular o espiritual e o social, fazendo do anúncio do Keryma um serviço e testemunho do Reino de Deus no mundo. Tal missão realizase no propósito conciliar de aggiornamento eclesial, situando a igreja no mundo em que vivemos, em diálogo e solidariedade com suas vicissitudes. ${ }^{9} \mathrm{~A}$ igreja partilha com o mundo sua história. A missão a impulsiona às diferentes realidades em que vive a humanidade, numa interação entre fé, cultura e política como possibilidades de concretização da mensagem proclamada.

\section{Desafios sociopolíticos que interpelam a missão em diálogo profético}

A atual realidade clama por um compromisso missionário transformador de uma igreja em saída, que se coloca em estado permanente de missão. A questão social política na qual vivem nossos povos torna-se cada vez mais desafiador para quem calça as sandálias da missão e sente-se pelo Espírito enviado/a ao mundo para proclamar as Boas Novas do Reino. Convivemos sob olhares e práticas unilaterais que fragmentam o desenvolvimento de verdadeiras ações políticas em favor da vida.

Nos tempos atuais, o desequilíbrio em diversos aspectos social, político religioso, econômico e ambiental leva a humanidade a sofrer tensões, conflitos e divisões fundadas sobretudo na cultura materialista globalizada. A opção pragmática e imediatista pelo materialismo e o capital financeiro sem critérios éticos, desafia o ser cristão e a realização da missão da igreja em diálogo com o mundo. Em não poucos ambientes a própria religião $e$ utilizada para interesses mercantilistas, manipulando sentimentos e crenças das pessoas não sem provocar conflitos e divisões também entre credos.

A igreja que tem a natureza missionária posiciona-se decididamente nesse contexto. Busca dar um testemunho visível e coerente, vinculando mística e ação profética. Em contexto brasileiro, serve como exemplo o grupo de bispos que corajosamente se manifestaram sobre o momento atual em que vive a sociedade brasileira, um dos períodos mais difíceis de sua história. ${ }^{10} \mathrm{O}$ contexto de pandemia do novo coronavírus revela de forma mais intensa outros graves problemas existentes em nosso país, tal como o avassalador colapso da economia, o crescimento do número de desempregados, empobrecidos e miseráveis, e a depredação ambiental, entre outros. Em meio a isso, vivemos

\footnotetext{
${ }^{9} \mathrm{GS} 1$.

${ }^{10}$ ZON PEREIRA, A. et al., Carta ao Povo de Deus.
} 
uma crise sem precedentes na assistência da saúde da população, agravado pela COVID-19. Em meio a isso, revela-se uma profunda crise política e de governança, que apresentamos em dois cenários:

\section{a) Cenário impactante}

Os tempos hodiernos desafiam a proposta do Evangelho do Reino apresentada por Jesus de Nazaré, e que por conseguinte, enfraquecem os relacionamentos entre pessoas e povos. Intensificam-se as situações de pobreza, fome e injustiça, guerras e migrações forçadas levam à morte milhões de pessoas em diversas regiões do planeta. Além disso, o crescente número de novas doenças, como a pandemia da COVID-19, assola vidas e agrava a situação de sofrimento físico, psíquico, espiritual, social e econômico.

Em meio a isso, as louváveis e significativas manifestações de solidariedade não são fortes o suficiente para a superação dos individualismos, dos interesses egoístas e do corporativismo das autoridades políticas que deveriam pensar o bem da coletividade. A corrupção desvia sem escrúpulos recursos que deveriam ser destinados para atender à população. No âmbito religioso, atitudes de intolerância, fundamentalismo e mercantilização da fé fortalecem uma cultura de violência, discriminação e preconceito. Acresce-se a isso, os projetos econômicos realizados às custas de acelerada degradação ambiental, como na região amazônica brasileira. E ainda mais, o enfraquecimento do exercício dos direitos humanos, o atenuado desemprego, a polarização política dos projetos para o enfrentamento da pandemia do novo coronavírus fragiliza e fragmenta o tecido social, causando sofrimento e mortes.

Esse impactante cenário exige repensar o modo de ser e de agir da igreja. Não satisfaz às exigências do Evangelho uma missão e uma igreja que seja indiferente a essa realidade. De alguma forma, a missão precisa contribuir para que instituições, líderes políticos e organizações civis superem projetos ideológicos fechados. A igreja "perita em humanidade", muito tem a contribuir para uma sociedade melhor, e nisso se vinculam fé e política, em sentido amplo, como compromissos em favor da vida humana e da criação, com particular atenção aos grupos humanos mais vulneráveis e excluídos nessa sociedade estruturalmente desigual, injusta e violenta. 
b) Cenário débil e incoerente

Lamentavelmente, o espaço político, que presenciamos, revela claramente a insensibilidade de quem politicamente governa sem paixão, e sem compaixão. Enquanto cidadãos e cidadãs, falta-nos uma análise realista e crítica da realidade que apresenta exigências específicas ao discipulado discípulo missionário que quer defender e promover a vida. Essas debilidades e vulnerabilidades mostram que o espaço da política enquanto lugar do bem comum é débil e incoerente frente ao projeto da vida em plenitude proposto por Jesus de Nazaré.

AConferência de Aparecida entende que torna-se cada vez mais complexa a realidade social e humana do nosso tempo. ${ }^{11}$ Há muitas feridas abertas que não chegam a cicatrizar. Muitas vezes onde se deveria existir um serviço fundamentado na solidariedade e na gratuidade - em organizações sociais e religiosas - constata-se forte expressão de personalismos, comportamentos individualistas e narcisistas, com projetos políticos e religiosos que servem mais de espetáculos nos quais sobressaem atores sem referências aos valores do Reino de Deus, que é a meta da Missio Dei. ${ }^{12}$ Urge ao cristão fiel seguidor de Jesus evitar a auto-referencialidade se de fato quer expressar a sensibilidade da igreja nas situações tão dolorosas que afetam a dignidade humana. ${ }^{13} \mathrm{O}$ momento histórico em que vive a humanidade pede à Igreja que mostre ao mundo um Deus sensível, compassivo, que "vê" a realidade, "ouve" o clamor, e "desce", caminha com o seu povo.

\subsection{O descrédito e a insegurança}

Tal contexto torna vulnerável todo esforço por real cidadania, porque se afirma num horizonte sociopolítico que não considera, efetivamente, o bem comum. A Conferência Nacional dos Bispos do Brasil (CNBB) tem constatado e denunciado, por diversas vezes, essa realidade. Mostra que na sociedade brasileira cada vez mais se desacredita dos dirigentes políticos. Esse descrédito

\footnotetext{
${ }^{11}$ DAp 36.

${ }^{12}$ O Conceito Missio Dei, indica que a missão não é, primeiramente, da Igreja, e sim de Deus que por amor cria e salva a humanidade. Essa missão se realiza, particularmente, na ação de Cristo e na força do Espírito, de modo que a missão é do Deus Triuno (BOSCH, D. J., Missão Transformadora, p. 470). A Igreja continua no mundo, a missão que Cristo deu aos discípulos. Nesse sentido, a Igreja não tem uma missão, mas é a missão que tem uma Igreja.

${ }^{13}$ DAp 48.
} 
mostra, de um lado, a criticidade crescente da população, que já não aguenta mais suportar benefícios e privilégios das elites governamentais. De outro lado, a falta de alternativas significativas na busca de líderes comprometidos com o bem comum aumenta a insegurança em que vivemos, o que é extremamente preocupante para o futuro da nação. ${ }^{14}$ Vivemos no Brasil o que constata o Papa Francisco também em outros países:

Uma cultura que envenena o Estado e suas instituições, permeando todos os estratos sociais, inclusive as comunidades indígenas. Trata-se de um verdadeiro flagelo moral; como resultado, perde-se a confiança nas instituições e em seus representantes, o que desacredita totalmente a política e as organizações sociais. ${ }^{15}$

Assim no âmbito da política brasileira, os cidadãos e as cidadãs estão à margem dos processos de participação e democratização. Mesmo as organizações não governamentais não conseguem ser expressivas em suas iniciativas locais ou nacionais. Não obstante, são louváveis as iniciativas realizadas com a valentia social e evangélica, que não apenas questionam e denunciam as injustiças, mas articulam, ainda que pouco, em ações concretas de transformação social que, com base à ética social e cristã, visam superar estruturas políticas e econômicas que atentam contra a vida humana e o meio ambiente. Teologicamente, vemos aqui um legítimo e necessário esforço de integração entre fé e política, afirmando posturas de solidariedade e responsabilidade para com a coletividade, construindo espaços sociais sustentados em políticas públicas, a afirmação de direitos e o empoderamento de pessoas e grupos das classes sociais mais desprotegidas. Fé e política estão juntas na construção de projetos democráticos e de uma efetiva cidadania.

Para isso, a missão da igreja precisa ser enraizada no Evangelho e na Doutrina Social do magistério eclesial. Com base ao Evangelho e à Doutrina Social da igreja, os/as discípulos/as missionários/as refazem sua compreensão da sociedade, da igreja e da missão. Trata-se de uma revisão que atualiza a compreensão da mensagem proclamada e amplia o seu horizonte profético. Para que tenha efetiva incidência social a fé não pode ser resumida a devoções fragmentadas, adesões a grupos seletivos, participação esporádicas e espiritualistas dos sacramentos, mera repetição de princípios doutrinais, moralismos que não expressam uma

${ }^{14}$ CNBB, Doc. 40, 191.

${ }^{15}$ Querida Amazônia, 24. 
vida cristã de fato convertida. Se tal for a vida cristã, a consequência será o enfraquecimento do compromisso público da fé.

Portanto, a igreja e a missão de proclamar uma mensagem de salvação sente-se interpelada pela consciência conciliar de que "as alegrias e as esperanças, as tristezas e as angústias dos homens de hoje, sobretudo dos pobres e de todos aqueles que sofrem, são também as alegrias e as esperanças, as tristezas e as angústias dos discípulos de Cristo". ${ }^{16}$ Somente assim fazendo toda a comunidade cristã partilhar "a alegria do Evangelho" como boa notícia e presença do Reino de Deus a todas as pessoas e aos povos do nosso tempo. ${ }^{17}$

\section{Jesus Cristo como modelo da missão em dialogo profético}

Deus nos chama e nos envia para o mundo em missão como seguidores de Jesus. Suess ${ }^{18}$ mostra como Jesus de Nazaré realiza a missão em diálogo inserido no coração da história e da cultura do seu tempo. Ele veio para derrubar os muros levantados pela corrupção do pecado e da injustiça, recuperando a imagem de Deus nos rostos humanos. Jesus de Nazaré é o missionário do Pai e na encarnação constrói a unidade entre pessoas e povos, com especial atenção à quem vive em situações de exclusão e marginalização. O Concilio Vaticano II propõe uma igreja para os nossos tempos que seja, de fato, seguidora dos passos de Jesus:

O Filho de Deus, pelo caminho de uma verdadeira Encarnação, veio fazer as pessoas participantes de sua natureza divina e, sendo rico, fez-se por nós necessitado para que nos tornássemos ricos da sua pobreza [...]. De si mesmo disse Cristo, a quem o Pai santificou e enviou ao mundo (Jo 10,36): "O Espírito do Senhor está sobre mim; por isso me ungiu e me enviou a anunciar a boa nova aos pobres, a sarar os contritos de coração, a proclamar a libertação dos cativos e a restituir a vista aos cegos" $(\operatorname{Lc} 4,18) .{ }^{19}$

Portanto, Jesus o enviado do Pai, envia a igreja no mesmo caminho da sua missão. E como Ele venceu as aspirações dos discípulos que queriam um Messias político e dominador, preferindo chamar-se Filho do homem que veio "para servir e dar a sua vida para redenção de muitos" (Mc 10,45), também a

\footnotetext{
${ }^{16}$ GS 1.

${ }^{17} \mathrm{EG} 16$.

${ }^{18}$ SUESS, P., Teologia da Missão, p. 181.

${ }^{19}$ AG 3.
} 
igreja é chamada a superar toda forma de auto-anúncio e auto-referencialidade. $\mathrm{O}$ anúncio deve acontecer no diálogo, na parceria e com a liberdade de aceitação, ou não, da parte dos ouvintes. A proposição do Evangelho não é imposição (Jo 18,37).O Reino não se propaga e nem se defende pela violência (Mt 26,51-53; Jo 18,36), e sim pelo testemunho, pelo diálogo e pela prática do amor, assumindo a cruz do mundo como solidariedade à cruz de Cristo, meio redentor da humanidade. ${ }^{20}$

\subsection{A missão dialógica e profética de Jesus}

De forma plausível, a ação missionaria de Jesus de Nazaré concretamente realizada em sua missão, confiada a Ele pelo Pai, revela que o seu testemunho é dar-se a si mesmo. A comunidade lucana compreendeu muito bem o jeito missionário de Jesus ao afirmar no seu Evangelho, "Eu devo anunciar a Boa Nova do Reino de Deus" (Lc 4,42). Aqui, seguramente, define-se a meta de toda a missão "Para isso é que fui enviado" (Lc 4,43). ${ }^{21}$ O Documento Diálogo e Missão descreve:

A vida de Jesus contém todos os elementos da missão. Segundo os Evangelhos, sua prática manifesta-se com o silêncio, com a ação, com a oração, com o diálogo e com o anúncio. A sua mensagem é inseparável da ação; anuncia Deus e o seu Reino, não só com as palavras, mas também com os fatos, e com as ações que realiza. Aceita a contradição, o insucesso e a morte; a sua vitória passa pelo dom da vida. ${ }^{22}$

Por isso, o Concilio Vaticano II, reconhece e renova essa compreensão ao afirmar que a prática missionária de Jesus desenvolve-se a partir de sua encarnação no meio da humanidade. Pelo despojamento (Fl 2,7) de si próprio, o Filho de Deus uniu-se de certo modo a todas as pessoas. Em sua missão Ele "trabalhou com mãos humanas, pensou com uma inteligência humana, agiu com uma vontade humana, amou com um coração humano. Nascido da Virgem Maria, tornou-se verdadeiramente um de nós, semelhante a nós em tudo, exceto no pecado". ${ }^{23}$

\footnotetext{
${ }^{20} \mathrm{DH} 11$.

${ }^{21}$ EN 6.

${ }^{22}$ SECRETARIADO PARA OS NÃO CRISTÃOS, Igreja e as outras religiões, 15.

${ }^{23}$ GS 22.
} 
Amaladoss ${ }^{24}$ afirma que a igreja autêntica, vivendo à maneira de Jesus de Nazaré, seguramente testemunha uma maneira diferente de viver e de se relacionar com a humanidade. Expressa um modo de ser e de agir que fala de forma mais convincente que as próprias palavras. Isso se expressa numa particular vivência do ensino do Sermão da Montanha, tendo nas Bemaventuranças um ideal de compromisso de vida cristã partilhada com os pobres, os mansos, os que têm fome e sede de justiça, os puros de coração, os que promovem a paz, os que são perseguidos por causa da justiça etc. (Mt 5,3-12). Hoje o discípulo missionário de Jesus é chamado a um modo alternativo de vida encarnando concretamente os valores do Reino. Isto é, dialogar profética e politicamente sobre situações de opressão e morte, não se intimidar frente aos conflitos, sejam eles de ordem política, econômica social ou religiosa.

Temos, felizmente, testemunhas dessa missão encarnada, como vivência convicta do discipulado. Destacamos Pedro Casaldáliga ${ }^{25}$ e sua compreensão de que o "Filho de Deus não se encarnou nas nuvens: Mas se encarnou em um ser humano, em um povo, em uma cultura, em uma estrutura e em uma conjuntura". E acrescenta, que "a Igreja não pode querer outra missão a não ser a missão de Jesus". Assim o Deus que é amor, veio dialogar com a humanidade, através do envio do Filho, Jesus de Nazaré.

Em vista disto, a Conferência de Aparecida alerta que o discípulo e missionário de Cristo que se empenha nos âmbitos da política, da economia e nos centros de decisões precisa estar permanentemente alerta aos ataques e influências de uma cultura dominada pelo materialismo, pelos interesses egoístas e por uma concepção da sociedade e da humanidade que se contradizem à ética do Evangelho. A política é uma forma privilegiada de exercer a caridade e, portanto, de afirmar o Evangelho. Para tal, é imprescindível que se fundamente no seguimento convicto de Jesus profeta do Reino. Nesse seguimento a presença pública da igreja contribui para a construção de consensos sobre os valores fundamentais que alicerçam a sociedade do nosso tempo, tal como a justiça, a liberdade e a fraternidade. ${ }^{26}$

\footnotetext{
${ }^{24}$ AMALADOSS, M., Missão e Inculturação, p. 71.

${ }^{25}$ CASALDÁLIGA, P., Opción por los pobres y espiritualidad, p. 49.

${ }^{26}$ DAp 506.
} 
2.2. A missão no horizonte do diálogo e da profecia

Etimologicamente profeta é alguém que fala adiante (do grego: pro ephein). ${ }^{27}$ Três elementos merecem destaque: 1) Ouvir a Palavra de Deus, e pelo dom da fé discernir e anunciar; 2) explicitar a vontade Deus e seu plano de salvação; 3 ) profetizar em nome de Deus, se preciso denunciando a vivência incoerente do povo em relação à dignidade de sua vocação. Portanto, a profecia nunca é a própria palavra, mas a Palavra de Deus. ${ }^{28}$ Assim sendo, a missão enquanto profecia é ação missionária em favor da justiça do compromisso com os pobres e os marginalizados socio-eclesialmente. A missão da igreja envolve espaços e pessoas além da própria igreja, visando assegurar que colaborem no suporte de políticas públicas que asseguram a justiça e a paz no mundo. ${ }^{29}$

Na teologia bíblica o profetismo é revelado por uma profunda experiência de Deus (Jr 1,4-10; Is 6,1-8). A profecia é mística. Os profetas são sempre fortalecedores/as de esperança em tempos difíceis. E assim é, felizmente, em muitos ambientes eclesiais e sociais em nossos tempos. Em contextos latinoamericano e brasileiro, por exemplo, como não se lembrar de Oscar Romero, Helder Câmara, Pedro Casaldáliga? Por eles, entre outros/as, a Boa Nova é, de fato, portadora de esperança, e a profecia é a forma mais eficaz de anunciar e transmitir a Boa Notícia do Reino. ${ }^{30}$

Wolff afirma que a Igreja em sua missão profética e missionária é vocacionada a sair de si mesma, descentrar-se e superar toda a tentação de auto-referencialidade. Urge superar toda pastoral de conservação e buscar uma prática pautada por condutas e ações condizentes com a novidade do Evangelho. E nisso, o "diálogo não é meio de evangelização, é o conteúdo da evangelização" no qual podemos perceber a revelação do amor de Deus que liberta e resgata a dignidade humana. E tal exige da igreja real inserção nos contextos político, econômico cultural e religioso em que vive o povo. ${ }^{31}$

\footnotetext{
${ }^{27}$ BEVANS, S.; SCHROEDER, R P., Diálogo profético, p. 74

${ }^{28}$ BEVANS, S.; SCHROEDER, R P., Diálogo profético, p. 74

${ }^{29}$ BEVANS, S.; SCHROEDER, R P., Diálogo profético, p. 111.

${ }^{30}$ CNBB, Doc. 80, p. 21-22.

${ }^{31}$ WOLFF, E., Igreja em Diálogo, p. 115-117.
} 
Costalunga ${ }^{32}$ mostra que tal é o que fez Jesus o qual, na força do Espirito, viveu a condição dos pobres e dos excluídos, pelo que foi caluniado, perseguido e morto. Essa é a condição dos missionários e das missionárias também dos nossos tempos. A fidelidade ao Mestre se concretiza nas lutas assumidas em favor da vida de quem Ele mesmo defendeu e defende. As situações da missão são os lugares teológicos a partir dos quais se realiza a Boa Nova do Reino a toda pessoa que a acolhe.

\section{A missão como pedagogia dialógica de fé e política}

O Papa Paulo VI sublinha na Evangelii Nuntiandi que a vocação específica da igreja é a evangelização inserida no mundo, em suas mais diversas tarefas. Nesta inserção, a primeira e imediata tarefa não é pelos trabalhos diretamente eclesiais, mas sim, o "pôr em prática todas as possibilidades cristãs e evangélicas escondidas, mas já presentes e operantes, nas coisas do mundo". ${ }^{33}$ Assim, o vasto campo e complicado da política e da realidade social é espaço da atividade evangelizadora da Igreja. Aqui são importantes a capacidade do diálogo, da cooperação, de estabelecer parcerias. A ação da igreja não acontece de forma isolada, como mostra Brighenti, porque "o isolamento é esterilizador", ${ }^{34}$ mas na comunhão dialogal com diferentes sujeitos sociais e eclesiais, visando a promoção de ações transformadoras em vista do bem comum. Neste sentido:

Trata-se de estabelecer uma relação de simpatia, que permite conhecer o outro. Por isso o diálogo exige uma relação horizontal, e só ele comunica e gera uma praxis criadora e transformadora. Por isso, se nutre do amor, da humildade e da confiança. $O$ antidiálogo quebra as relações, estabelece uma relação vertical, desamorosa, arrogante, desesperançosa, auto suficiente. Não é possivel uma relação entre sujeitos, numa relação dominante. ${ }^{35}$

Desse modo, a integração da fé com os elementos socioculturais construirá novos caminhos e pontes para o desenvolvimento de ações eclesiais em diálogo com diferentes espaços e diferentes sujeitos, cristãos e

32 COSTALUNGA, A., Globalização excludente, trindade e evangelização, no contexto do Continente Americano, p. 107.

${ }^{33}$ EN 70.

${ }^{34}$ BRIGHENTI, A., Por uma evangelização inculturada, p. 96.

${ }^{35}$ BRIGHENTI, A., Por uma evangelização inculturada, p. 72. 
não cristãos, crentes e não crentes, mas que eticamente se situam no horizonte evangélico do Reino. Tal parceria há de construir o desenvolvimento integral do ser humano e a cooperação pra a superação de todas as formas desumanas que afligem a humanidade. Neste sentido, na busca de critérios e valores em vista do bem comum, é indispensável entender a presença pública da igreja como diálogo e parceria com a comunidade civil e politica. ${ }^{36}$

A relevância desse caminho dialogal em vista do bem viver coletivo, é bem expresso também por Wolff:

O testemunho e a missão são vividos como serviço que se fundamenta na gratuidade da proposta do Evangelho pregado. Acredibilidade do Evangelho é comprometida quando se pratica a missão em conflitos e oposição aos outros. A missão não é ganhar, conquistar, concentrar. Evangelizar é uma partilha autentica da graça de Deus, da vida em abundância oferecida em Cristo por meio do Espirito Santo [...]. O cenário plural da sociedade hodierna tem o potencial de constituir-se em um laboratório de articulação dialogal em prol de princípios teológicos e pastorais relevantes para o ser e a missão da Igreja em nossos tempos. ${ }^{37}$

Nesta sequência sendo a fé relação, urge cada vez mais o exercício da capacidade de escuta, do reverter as posturas e refazer o caminho se necessário for. Enquanto seres humanos, somos constituídos por relações. O nosso desenvolvimento acontece pelo processo de relação com as outras pessoas e o meio. Viver é conviver em diferentes dimensões da existência, "em atitude comunional e integradora... (comunhão) divina, cósmica e sobrenatural". ${ }^{38}$ Acrescenta Wolff, que a dimensão do dom da fé deve nos levar a assumir a lógica das maiorias que sofrem injustamente, sobretudo pelos regimes totalitários. Os contextos sociais e políticos provocam as igrejas a se integrarem nos movimentos que buscam a transformação de situações de injustiça. Esses movimentos que buscam transformação social reclamam pelo compromisso da igreja pelas suas causas por justiça socioambiental. ${ }^{39}$

\footnotetext{
${ }^{36}$ CNBB, Doc. 80, p. 63.

${ }^{37}$ WOLFF, E., Por uma evangelização inculturada, p. 116

${ }^{38}$ WOLFF, E., Unitatis Redintegratio, Dignitatis Humanae, Nostra Aetate, p. 151.

${ }^{39}$ WOLFF, E., O contexto ecumênico da Conferência de Puebla e suas contribuições para a unidade cristã, p. 260
} 


\subsection{Premissas}

Para melhor compreendermos como a missão em diálogo pode contribuir para uma ação transformadora que integra fé e política, é importante termos claro algumas premissas. São dados que impulsionam a vivência da missão não de maneira dicotômica, desligada do contexto vital da sociedade, mas constituída nesse contexto, onde se expressa o compromisso político e transformador da fé cristã:

a) A Igreja sempre tem assumido o dever de agir pelo bem comum; e, procedendo assim, também educa bons cidadãos para a atuação pública de forma mais direta. Além disso, ela ensina que o dever fundamental do poder é a solicitude pelo bem comum da sociedade; daqui dimanam os seus direitos fundamentais. ${ }^{40}$

b) Enquanto comunidade política o Estado é essencial para a organização da sociedade e deve contribuir para afirmar que o povo é soberano do próprio destino. Isso requer a participação da sociedade para que seja possível o exercício democrático do poder público. Do contrário, a sociedade civil será condicionada a assistir uma imposição do poder por parte de um determinado grupo a todos os outros membros da mesma sociedade. ${ }^{41}$

c) Tendo em conta as reais condições de cada povo e o necessário vigor da autoridade pública, em nossa época, em que tem crescido enormemente a consciência social das pessoas, urge fortalecer a participação dos cidadãos na vida política da comunidade.

d) $\mathrm{O}$ bem comum que se encontra sob o serviço da autoridade do Estado, será "plenamente realizado somente quando todos os cidadãos estiverem seguros dos seus direitos. Sem isto, chega-se ao descalabro da sociedade, à oposição dos cidadãos". ${ }^{42}$ Por conseguinte, os cidadãos sofrerão situações de opressão, de intimidação e de violência, como inúmeros exemplos de totalitarismos na história da humanidade.

e) Quando o bem comum torna-se utilidade particular, a sociedade se fragiliza. Tendo em vista que no bem comum, todos e cada um têm

\footnotetext{
${ }^{40} \mathrm{RH} 17$.

${ }^{41}$ RH 17.

${ }^{42}$ RN 30
} 
direitos e deveres, a totalidade da vida social é o lugar da realização dos direitos de todos os cidadãos e cidadãs. ${ }^{43}$

f) Torna-se cada vez mais irritante, quando a sociedade "veem crescer o câncer social da corrupção profundamente radicada em muitos países - nos seus Governos, empresários e instituições - seja qual for a ideologia política dos governantes". ${ }^{44}$

g) Temos consciência de que a justa ordem da sociedade e do Estado seja dever central da política. Todavia a igreja não pode nem deve ficar à margem na luta pela justiça. "Todos os cristãos, incluindo os Pastores, são chamados a preocupar-se com a construção dum mundo melhor". ${ }^{45}$

h) "A justa ordem da sociedade e do Estado é dever central da política. Um Estado, que não se regesse segundo a justiça, reduzir-se-ia a um grande bando de ladrões, como disse Agostinho uma vez: "itaque iustitia quid sunt regna nisi magna latrocinia?". ${ }^{46}$

i) $\mathrm{O}$ atual contexto histórico no qual vivemos urge a criação de novos estilos de ação política que valorizem as iniciativas populares de grupos e comunidades. Tal atitude favorecerá a participação democrática e efetiva de cidadania, e tornar-se-á possível por ações políticas incidentes na organização do bem comum. ${ }^{47}$

j) O empenho político do povo de Deus é uma expressão qualificada e exigente do empenho cristão a serviço dos outros. Por este caminho, pode-se chegar a uma verdadeira santidade política. ${ }^{48}$

k) As comunidades estão incumbidas de discernir, com a ajuda do Espírito Santo, em diálogo com os outros irmãos cristãos e com todos os homens de boa vontade, as opções e os compromissos que convém tomar para realizar as transformações sociais, políticas e econômicas que se apresentam como necessárias e urgentes. ${ }^{49}$

\footnotetext{
${ }^{43} \mathrm{RN} 31$

${ }^{44}$ EG 60.

${ }^{45} \mathrm{EG} 183$.

${ }^{46}$ DCE 28.

${ }^{47}$ CNBB, Doc. 80 , p. 65-66.

${ }^{48} \mathrm{OA} 46$.

${ }^{49} \mathrm{OA} 4$.
} 
Conclui-se que tais premissas corroboram o ensino do Concílio Vaticano II onde se afirma que o desenvolvimento da pessoa humana e o progresso da sociedade estão em mútua dependência. Por sua natureza a pessoa humana necessita da vida social e política. E isso não é sem implicações para a sua fé. Ao relacionar-se, os contatos sociais de quem crê são orientados pelos princípios de sua fé. É isso que torna as pessoas crentes capazes de responder à própria vocação, ao serviço no mundo e ao diálogo e cooperação com todas as pessoas. ${ }^{50}$ Isso é cidadania, é fé e é política.

Mesmo que o termo "político" nem sempre tenha essa conotação ampla no cotidiano social, é preciso afirmá-lo, legitimando a presença e ação pública da igreja. É o que se desenvolve hoje pela "teologia pública", que para alguns possui uma epistemologia própria, ${ }^{51}$ para outros é uma forma de atualizar em nossos tempos a teologia da libertação ou teologia do político. Não entramos aqui nesse debate. Importa retomar o sentido etimológico do conceito grego politéia, que deriva de pólis, cidade-estado, mostrando que sua atuação ética é fundamental para o desempenho da gestão pública, com implicações diretas no desenvolvimento humano e social. Por isso, se alguém sente-se capacitado/a para entrar na ação política partidária, num contexto de legítimo pluralismo partidário, como cristão/ã é importante buscar uma coerência entre os seus projetos e o Evangelho, dando testemunho dos compromissos de fé mediante um serviço eficaz e desinteressado para o bem viver da comunidade. ${ }^{52}$ Nesse sentido, repetidas vezes a doutrina social da Igreja afirma que a política é uma forma privilegiada para exercer a caridade evangélica.

Tal é o que foi assinalado pelo terceiro simpósio internacional de missiologia, realizado de 08 a 12 de dezembro de 2008 em Quito, mostrando que a presença missionária da igreja na sociedade é impactada pelas realidades socioculturais, políticas e econômicas, além da religiosa. A missão da igreja consiste em gerar esperança em meio às situações sombrias e difíceis que vivem os povos. ${ }^{53}$ Por isso, o/a discípulo/a missionário/a, não pode permanecer morno ou morna diante da realidade que o circunda, pois a vivência do "amor e benevolência de modo algum nos devem tornar indiferentes perante a verdade e o bem". ${ }^{54}$ Isso exige uma esclarecida e evangélica opção política

\footnotetext{
${ }^{50}$ GS 25.

${ }^{51}$ VON SINNER, R., Teologia Pública no Brasil e na África do Sul.

${ }^{52}$ OA 24 e 46.

${ }^{53}$ RAMÍREZ, S., Dios en la humanidad misión de dios, p. 23 e 47.

${ }^{54}$ GS 28.
} 
de todas as pessoas crentes. E dessa forma elas contribuem na missão que a igreja recebeu de Jesus: possibilitar que os surdos ouçam, os cegos vejam, os famintos sejam saciados, os enfermos sejam curados, os oprimidos sejam libertados. Gerando uma comunidade onde se vivem as Bem-Aventuranças. Então, a igreja, enquanto sinal do Reino, é, de fato, instrumento da "vida em abundância" (Jo 10,10). E isso requer a formação de consciência crítica e libertadora para colaborar evangélica e politicamente na Missio Dei.

\section{Conclusão}

A missão em diálogo enquanto cooperação na Missio Dei revela que a fé é dom de Deus e impulsiona a igreja ao compromisso transformador do mundo. A práxis missionária tem implicações socioculturais, políticas e econômicas, além de religiosas. Justifica-se, portanto, que a fé tem uma dimensão política na medida em que motiva as pessoas crentes no serviço ao bem comum a partir dos valores do Evangelho. Tudo o que se relaciona na busca do bem comum, pode-se entender como política, embora por vezes esteja marcada por interesses contraditórios ao que esse termo significa e à sua relação com o Evangelho.

Sendo assim, faz-se necessário, que os cristãos e as cristãs solidificados/ as pela fé em Cristo, assumam de forma consciente e responsável o seu lugar social, discernindo as realidades que exigem transformação para que o Reino possa se manifestar na história humana. Para isso, somos movidos pelo Espírito que nos concede o dom da profecia e nos move pela esperança que não decepciona ( $\mathrm{Rm} 5,5)$. A opção pelo Reino exige colocar a mão no arado e olhar sempre adiante (Lc 9,62). Fé e política são duas mãos no trabalho do Reino. Tal é o verdadeiro e completo culto a Deus, que não se limita à presença no templo. Liturgia é serviço à vida do e no mundo, pelo engajamento nas causas que realizam a justiça evangélica. Desse modo, como igreja, recuperamos o verdadeiro significado de "política", ao mesmo tempo em que damos real vivência ao que entendemos por "fé cristã".

\section{Referências bibliográficas}

AMALADOSS, M. Missão e Inculturação. São Paulo: Loyola, 2000.

BÍBLIA de Jerusalém. São Paulo: Paulus, 2002. 
BENTO XVI, PP. Carta encíclica Deus caritas est sobre o amor cristão. São Paulo: Paulinas, 2006.

BEVANS, S. B.; SCHROEDER, R. P. Diálogo profético: Reflexões cristãs hoje. São Paulo: Paulinas, 2016.

BRIGHENTI, A. Por uma evangelização inculturada. Princípios pedagógicos e passos metodológicos. São Paulo: Paulinas, 1998.

CASALDÁLIGA, P. Opción por los pobres y espiritualidad. In: VIGIL, J. M. (Org). Sobre la opción por los pobres. Quito-Ecuador: Abya-yala, 1998. p. 47-56.

CELAM. Documento de Aparecida: Texto conclusivo da V Conferência Geral do Episcopado Latino-Americano e do Caribe. Brasília: Edições CNBB; São Paulo: Paulinas / Paulus, 2007.

CNBB SUL 2. Os cristãos e as eleições. Cartilha de Orientação Política. Curitiba: CNBB, 2020.

CNBB. Igreja: Comunhão e Missão na Evangelização dos povos no mundo do trabalho, da política e da cultura. São Paulo: Paulinas, 1988. (Doc. 40).

CNBB. Evangelização e missão profética da Igreja: novos desafios. São Paulo: Paulinas, 2005. (Doc. 80).

CONCÍLIO VATICANO II. Constituição Pastoral Gaudium et Spes sobre a Igreja no mundo de hoje. In: DOCUMENTOS DO CONCÍLIO VATICANO II. São Paulo: Paulus, 2007. p. 539-661.

CONCÍLIO VATICANO II. Constituição Dogmática Lumen Gentium sobre a Igreja. In: DOCUMENTOS DO CONCÍLIO VATICANO II. São Paulo: Paulus, 2007. p. 101-197.

CONCÍLIO VATICANO II. Declaração Dignitatis humanae sobre a liberdade religiosa. In: DOCUMENTOS DO CONCÍLIO VATICANO II. São Paulo: Paulus, 2007. p. 411-429.

CONCÍLIO VATICANO II. Decreto Ad Gentes sobre a atividade missionária da Igreja. In: DOCUMENTOS DO CONCÍLIO VATICANO II. São Paulo: Paulus, 2007. p. 431-489.

COSTALUNGA, A. Globalização excludente, trindade e evangelização, no contexto do Continente Americano. São Paulo, 2013. 211p. Dissertação. Faculdade de Teologia, Pontifícia Universidade Católica de São Paulo. 
FRANCISCO, PP. Exortação Apostólica Evangelii Gaudium - A alegria do evangelho. São Paulo: Paulinas, 2013.

FRANCISCO, PP. Exortação Apostólica Pós-Sinodal Querida Amazônia - Ao povo de Deus e a todas as pessoas de boa vontade. São Paulo: Paulus, 2020.

JOÃO PAULO II, PP. Carta Encíclica Redemptor Hominis sobre o Redentor do Homem. São Paulo: Loyola, 1979.

LEÃO XIII, PP. Carta Encíclica Rerum Novarum sobre a condição dos operários. São Paulo: Paulinas, 2011.

BOSCH, David J. Missão Transformadora: mudança de paradigmas na teologia da missão. São Leopoldo: EST/Sinodal, 2007.

PAULO VI, PP. Carta Apostólica Octogesima Adveniens, por ocasião do $80^{\circ}$ aniversário da encíclica Rerum Novarum. São Paulo: Paulinas, 2011.

PAULO VI, PP. Exortação Apostólica Evangelii Nuntiandi sobre a evangelização no mundo contemporâneo. São Paulo: Paulinas, 2011.

RAMÍREZ, S. Dios en la humanidad misión de dios: una familia de toda la humanidad. In: SIMPÓSIO INTERNACIONAL DE MISIONOLOGÍA, $3^{\circ}$., 2008, Quito. Anais do $3^{\circ}$ Simpósio Internacional de Misionología. Quito: Comissão Teológica do Congresso Americano Missioneiro - CAM 3, 2008. p. 23-47.

WOLFF, E. O contexto ecumênico da Conferência de Puebla e suas contribuições para a unidade cristã. Atualidade Teológica, v. 23, n. 62, p. 253-277, mai./ago. 2019. Disponível em: <https://www.maxwell.vrac.pucrio.br/46108/46108.PDFXXvmi=>. Acesso em: 15 out. 2020. DOI: https:// doi.org/10.17771/PUCRio.ATeo.46108.

WOLFF, E. Igreja em Diálogo. São Paulo: Paulinas, 2018.

WOLFF, E. Unitatis Redintegratio, Dignitatis Humanae, Nostra Aetate: textos e comentários. São Paulo: Paulinas, 2012.

SECRETARIADO PARA OS NÃO CRISTÃOS. Igreja e as outras religiões: Diálogo e Missão. São Paulo: Paulinas, 1984.

SUESS, P. Teologia da Missão. In: LABONTÉ, G.; ANDRADE, J. (Orgs). Caminhos para a Missão: fazendo missiologia contextual. Brasília: abcBSB Editora, 2008. p. 149-190. 
VON SINNER, R. Teologia Pública no Brasil e na África do Sul. Um diálogo teológico-político. São Leopoldo: Sinodal / EST, 2020.

ZON PEREIRA, A. et al. Carta ao Povo de Deus, 22 de julho de 2020. Disponível em: <https://cebsdobrasil.com.br/carta-dos-bispos-ao-povo-dedeus/>. Acesso em: 14 out. 2020.

\section{Elias Wolff}

Doutor em Teologia pela Pontificia Università Gregoriana Docente na Pontifícia Universidade Católica do Paraná Curitiba / PR - Brasil E-mail: elias.wolff@facasc.edu.br

Recebido em: 31/08/2020 Aprovado em: 19/11/2020 